\title{
Surface Treatment of Cement-Based Materials with $\mathrm{NanoSiO}_{2}$
}

\author{
Pengkun Hou and Xin Cheng \\ School of Materials Science and Engineering, University of Jinan \\ Shandong Provincial Key Laboratory of Preparation and Measurement of Building Materials \\ Jueshi Qian \\ College of Materials Science and Engineering, Chongqing University \\ Surendra P. Shah \\ Department of Civil and Environmental Engineering, Northwestern University
}

\begin{abstract}
A dense surface structure of cement-based material is favorable for its resistance to the impacts of environment. In this work, effectiveness and mechanisms of the surface treatment of cement-based materials with nanoSiO of different states, that is, colloidal nanoSiO ${ }_{2}$ (CNS) and the in situ formed nanoSiO ${ }_{2}$ gel through the hydrolysis of its precursor of tetraethoxysilane (TEOS), by brushing and soaking techniques, were investigated. Results showed that both CNS and TEOS are capable of reducing the liquid and gaseous transport properties of hardened cement-based materials, although at a different extent. It revealed that the pozzolanic reactivity and the filler effect of nanoSiO ${ }_{2}$ are the main causes for the refining of the threshold size and the reduction of volume of the capillary pores, and they finally lead to a linearly reduction of the transport property. From this study, it can be reflected that surface treatment of cement-based materials with nanoSiO ${ }_{2}$ would be an optimal alternative of making concrete structure more durable.
\end{abstract}

Keywords: cement-based materials, CNS, TEOS, durability, nanoSiO ${ }_{2}$.

\section{INTRODUCTION}

During the service life of cement-based material, the influences of environment would lead to the decrease of its quality by the migration of harmful substances inward/outward of its surface (Basheer, Basheer, \& Cleland, 1997). The densification of the surface of hardened cement-based material will result in a significant improvement of the quality of the entire structure (Basheer et al., 1997; Jiang, Long, \& Sun, 2009; Scarfato, Maio, \& Fariello, 2012).

To make a dense structure, pozzolanic material was introduced into cement-based materials, and additional $\mathrm{C}-\mathrm{S}-\mathrm{H}$ gel could be formed through its reaction with the hydration product of calcium hydroxide $(\mathrm{CH})$ of cement. As a siliceous material, nanoSiO $\mathrm{S}_{2}$ has been intensively studied in cement and concrete (Delucchi, Barbucci, \& Cerisola, 1997). It exhibits a very fine particle size (about several to $100 \mathrm{~nm}$ ) and an extremely high pozzolanic reactivity. The nanosized particle size feature of nanSiO $\mathrm{S}_{2}$ would be favorable for its penetration into the pores. Kupwade-Patil et al. used nanoparticles for the treatment of reinforced concrete to reduce the corrosion of ion bars, whose results support the sealing effect of nanoparticles on concrete (Sandrolini, Franzoni, \& Pigino, 2012).
Realizing both the importance of surface treatment of cement-based materials and the properties of nanoSiO ${ }_{2}$, we studied the possibility of applying this fine and pozzolanic-reactive silicious material for the surface treatment of hardened cementbased materials. To facilitate the penetration of the pozzolan into pores, a colloidal nanoSiO $\mathrm{S}_{2}(\mathrm{CNS})$ and its precursor of tetraethoxysilane (TEOS, which was reported as pozzolanic reactive; Khatib \& Mangat, 1995) were applied onto the surface of the hardened cement-based materials, and their effects and mechanisms on surface treatment were investigated and compared.

\section{MATERIALS AND METHODS}

\subsection{Materials}

Ordinary Portland cement complying to Chinese standard GB 175-2007 was used in this work, and its physiochemical properties are listed in Table 1.

Table 1. Physiochemical properties of cement.

\begin{tabular}{cccccccc}
\hline $\mathrm{SiO}_{2}$ & $\mathrm{Al}_{2} \mathrm{O}_{3}$ & $\mathrm{Fe}_{2} \mathrm{O}_{3}$ & $\mathrm{SO}_{3}$ & $\mathrm{CaO}$ & $\mathrm{MgO}$ & $\mathrm{LOI}$ & $\begin{array}{c}\text { 28-Day } \\
\text { Compressive } \\
\text { strength (MPa) }\end{array}$ \\
\hline 21.1 & 4.7 & 3.5 & 3.3 & 62.9 & 2.8 & 1.1 & 50.1 \\
\hline
\end{tabular}


Commercially available colloidal nanoSiO $\mathrm{S}_{2}(\mathrm{CNS})$ with solid content of $30 \%$ was used. Morphologic graphs shown in Figure 1 indicate that CNS particles are round in shape. The dark spot in TEM image indicates that some seriously agglomerated clusters may be seen in CNS. Chemical grade tetraethoxysilane (TEOS) with the mass content of $30 \%$ was used. TEM image shown in Figure 1(c) is the hydrolysis product of TEOS when mixed with saturated lime solution at a volume ratio of $1: 1$, which shows a nanosized structure.
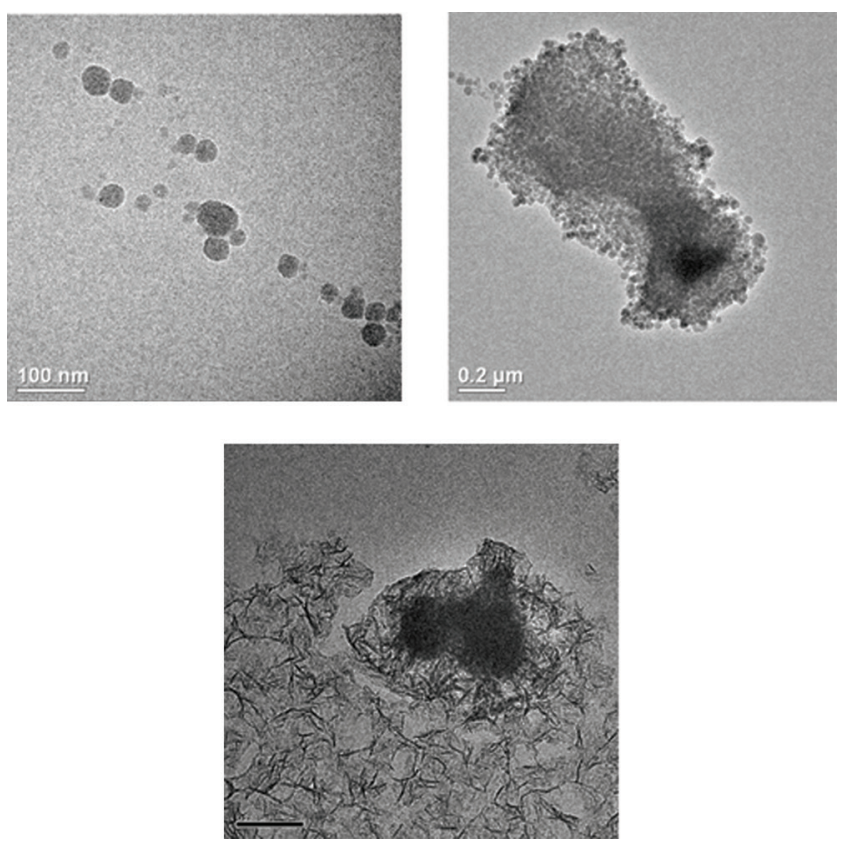

Figure 1. TEM image of CNS-20 nm (a, b) and hydrolysis products of TEOS (c).

Polycarboxylate (PC) water reducer with solid content of $40 \%$ and water-reducing ratio of $30 \%$ was used to make a small water-to-cement (w/c) paste. For the relatively high w/c cement pastes, cellulose thickening agent was used to avoid any segregation of the pastes. To eliminate the air bubble content in the pastes, $0.3 \%$ organosilane-based defoamer was added into each mix.

\subsection{Methods}

\subsubsection{Sample preparation}

Mortar samples with w/c ratios of 0.4 and 0.6 and a cement-to-sand ratio of $1 / 3$ were prepared. The fineness modulus of the river sand was 2.8. After mixing, mortars were cast in $4 \mathrm{~cm} \times 4 \mathrm{~cm} \times 16 \mathrm{~cm}$ rectangular molds and covered with plastic sheet and cured for 1 day at ambient environment (about $25^{\circ} \mathrm{C} / 60 \% \mathrm{RH}$ ) before been demolded and stored in curing chamber at $20 \pm 1^{\circ} \mathrm{C}$ and $\mathrm{RH} 95 \%$ until surface treatment.
Cement pastes with $w / c$ ratios of $0.26,0.38,0.6$, and 1.0 were prepared. Before mixing, water, defoamer, PC (if any), and cellulose thickening agent (if any) were homogeneously mixed. Cement pastes were cast in steel mold with dimensions of $4 \mathrm{~cm} \times 4 \mathrm{~cm} \times 16 \mathrm{~cm}$. Samples were demolded 2 days after casting and cured in standard curing chamber $\left(21^{\circ} \mathrm{C}, 95 \% \mathrm{RH}\right)$ for 26 days. Samples used for the measurement of water vapor transmission coefficient were cast in plastic beakers with diameter of $80 \mathrm{~mm}$, and the demolding and curing processes were same to those for waterabsorption ratio measurement.

\subsubsection{Surface treatment}

For mortars, the 1-month old samples were cut into small pieces with dimensions of $4 \mathrm{~cm} \times 4 \mathrm{~cm} \times 1 \mathrm{~cm}$. The slices were then dried at $60^{\circ} \mathrm{C}$ for 1 day before been surface treated with CNS and TEOS by brushing technique. The surface was treated for three times at a time interval of $20 \mathrm{~min}$. A saturated wet condition was achieved after each brushing.

For cement pastes, after 28-day curing, samples were cut into small pieces with dimensions of $4 \mathrm{~cm} \times 4 \mathrm{~cm} \times 2 \mathrm{~cm}$ and $\Phi 8 \mathrm{~cm} \times 1.5 \mathrm{~cm}$ using a water-cooling saw. Sectioned samples were vacuum dried at $40^{\circ} \mathrm{C}$ for $24 \mathrm{~h}$ before being soaked in surface treatment solutions (water, CNS, and TEOS) for $1 \mathrm{~h}$, and then samples were removed from the solutions and continuously cured in standard condition $\left(21^{\circ} \mathrm{C}\right.$, 95\% RH) for another 7 days. Compared with mortar samples, a longer contacting time of pastes with treatment solution is to get a better treatment effect.

\subsubsection{Water absorption ratio}

Water absorption ratios of mortar and paste samples were measured to access the surface treatment effects of CNS and TEOS. For each test, the water absorption ratios of three replicates at 10, 20, 40, $90 \mathrm{~min}$ and $24 \mathrm{~h}$ water-soaking time were tested and averaged to be taken as the representative value. Based on the water absorption ratio results, the initial water absorption coefficient, that is, slope of the water absorption ratio vs. square root of time (in second) at the beginning of water absorption described in ASTM Committee (2000) was adopted to reflect the water transport properties.

\subsubsection{Water vapor transmission coefficient}

"Wet-cup" method (Franzoni, Pigino, \& Pistolesi, 2013) was used to reflect the water vapor transport properties of cement pastes. During the test, weight loss of the plastic cup, which is caused by the migration of water vapor from the constant high humidity chamber to the constant low humidity chamber through the sample, (with a thickness of $1.5 \mathrm{~cm}$ ) was recorded, and the slope of the weight loss vs. time curve was used to reflect water vapor transport property of the sample. 
Pure water and saturated $\mathrm{KBr}$ solution was used to achieve the constant high and low humidity of about 100 and $80 \%$.

\subsubsection{SEM}

Quanta FEG-250 was used to analyze the morphology of the cross-section of the hardened cement mortar before and after CNS/TEOS treatment. When preparing sample for SEM test, the surface treated and cured mortar slice was fractured and then the fractured new surface within $2 \mathrm{~mm}$ from the edge of the CNS/TEOS-treated side was tested.

\subsubsection{IR and $X R D$}

As CNS condensed on the surface of hardened cement mortar would overlap the characteristic peaks of cement paste, thus IR spectroscopic experiments were conducted on Thermo Nicolet, Nexus 870, USA, to detect whether CNS hydrates on the surface of hardened cement paste. Sample was scanned 32 times with a resolution of $4.0 \mathrm{~cm}^{-1}$.

X-ray diffractometry (Bruker D8 Advance, Germany) was used to determine the influence of TEOS on the mineralogy of cement paste of a w/c ratio of 0.35 . Cement paste was hand mixed for 3 min at ambient environment (about $25^{\circ} \mathrm{C} / 60 \% \mathrm{RH}$ ) and then cast in the plastic plate dedicated for XRD testing. Samples were covered with thin plastic foil to avoid water evaporation. CNS/TEOS was brushed onto the surface of the cement paste hardened for $6 \mathrm{~h}$, and then the treated samples were cured at $20^{\circ} \mathrm{C} / 95 \%$ $\mathrm{RH}$ until test. After surface determination, samples were polished with abrasive polishing paper to a depth of about 1-2 $\mathrm{mm}$, and then the inner paste was determined again with XRD to reflect the influence of CNS/TEOS on mineralogy of the inner cement pastes.

\subsubsection{MIP}

QuantachromePoreMaster (USA) was used to investigate the pore structure of hardened mortar and paste. The surface-treated samples were broken into small pieces and soaked in acetone for 1 day and then vacuum oven dried at $110^{\circ} \mathrm{C}$ for $24 \mathrm{~h}$ before measurement.

\section{RESULTS AND DISCUSSIONS}

\subsection{Liquid and gaseous transport properties}

Influences of the surface treatment of CNS/TEOS on the water absorption ratios of mortars are shown in Figure 2. Results of samples cured at $50^{\circ} \mathrm{C} / 95 \% \mathrm{RH}$ were compared with those obtained from samples
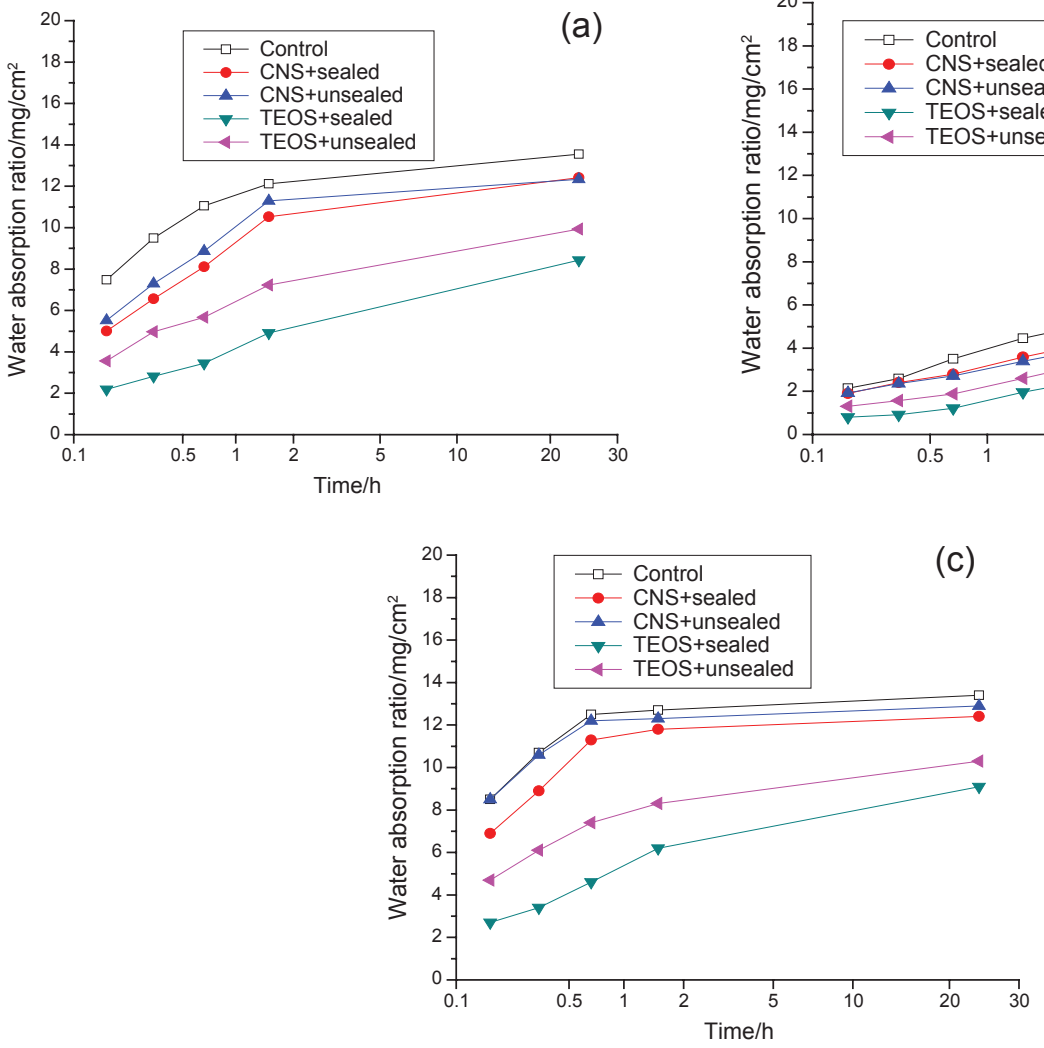

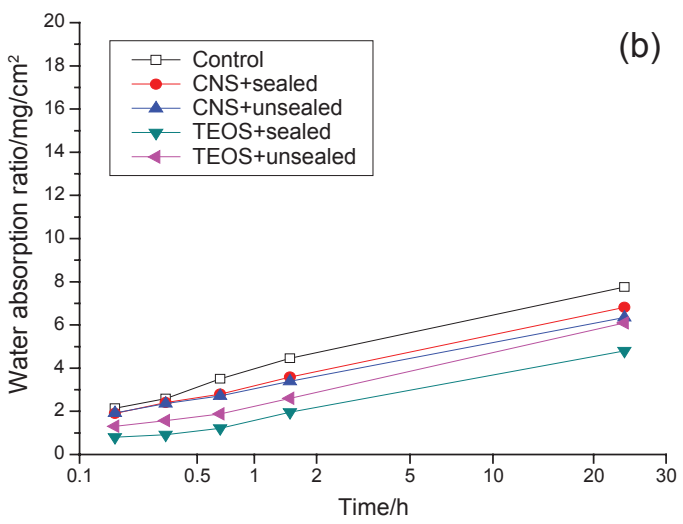

(c)

\section{(b)}


cured at $20^{\circ} \mathrm{C} / 95 \% \mathrm{RH}$. Meanwhile, to diminish the influence of the condensation of CNS that would be detrimental for its penetration into the pores of hardened mortar during water loss while curing, the CNS/TEOS-treated samples were sealed.

It can be seen that under most curing regimes, the water absorption ratio decreases when CNS/TEOS is applied onto the surface of mortar and greater reductions can be found in TEOS-treated samples. It also shows in Figure 2(c) that no surface sealing effect is found in CNS-treated mortar cured at $20^{\circ} \mathrm{C}$ under unsealed condition, and this complies well with results reported by Franzoni et al. (2013). However, when comparing the water absorption ratios of samples cured at $20^{\circ} \mathrm{C}$ shown in Figure 2(c) and $50^{\circ} \mathrm{C}$ shown in Figure 2(a), it can be seen that a higher curing temperature is favorable for a greater reduction of water absorption ratio. This could be due to that a greater pozzolanic reaction happens at a higher curing temperature. A greater reduction of water absorption ratio in TEOS-treated and sealed sample to that of CNS-treated and sealed sample could be ascribed to a greater penetration ( $\mathrm{Yu}$, Kirkpatrick, \& Poe, 1999) and/or pozzolanic reaction extent of TEOS.

Similar to the mortar sample tests, water absorption characteristics of cement paste samples were tested, and the initial water absorption coefficients of samples treated with water, CNS, and TEOS are exhibited in Table 2. Results show that the water absorption rate of the sample decreases when CNS and TEOS treatments are applied. Similar to the water absorption ratio results, a greater reduction of the initial water absorption rate can be found in TEOS-treated sample.

Table 2. Initial water absorption coefficients of cement pastes $/\left(\mathrm{mg} / \mathrm{cm}^{2 *} \mathrm{~s}^{1 / 2}\right)$.

\begin{tabular}{lcccc}
\hline w/c & $\mathbf{0 . 2 6}$ & $\mathbf{0 . 3 8}$ & $\mathbf{0 . 6}$ & $\mathbf{1 . 0}$ \\
\hline Control & $2.5(100 \%)$ & $5.7(100 \%)$ & $6.9(100 \%)$ & $8.3(100 \%)$ \\
CNS & $2.5(100 \%)$ & $5.7(100 \%)$ & $5.7(82.6 \%)$ & $6.3(75.9 \%)$ \\
TEOS & $2.5(100 \%)$ & $4.2(73.7 \%)$ & $5.2(75.4 \%)$ & $5.5(66.3 \%)$ \\
\hline
\end{tabular}

Using the "wet-cup" method, the water vapor permeability of hardened cement pastes with various w/c ratios was tested, and the results are shown in Figure 3. It shows that the surface treatment of cement pastes with CNS and TEOS greatly decrease the water vapor permeability coefficient. A negligible reduction degree is seen in CNS-treated paste at a $w / c$ of 0.26 , reflecting that little CNS penetrates into the pore structure. A small pore-filling effect shown in Figure 3 at a high w/c ratio may be due to that large pores would take a great part and cannot be fully refined with nanosized particles.

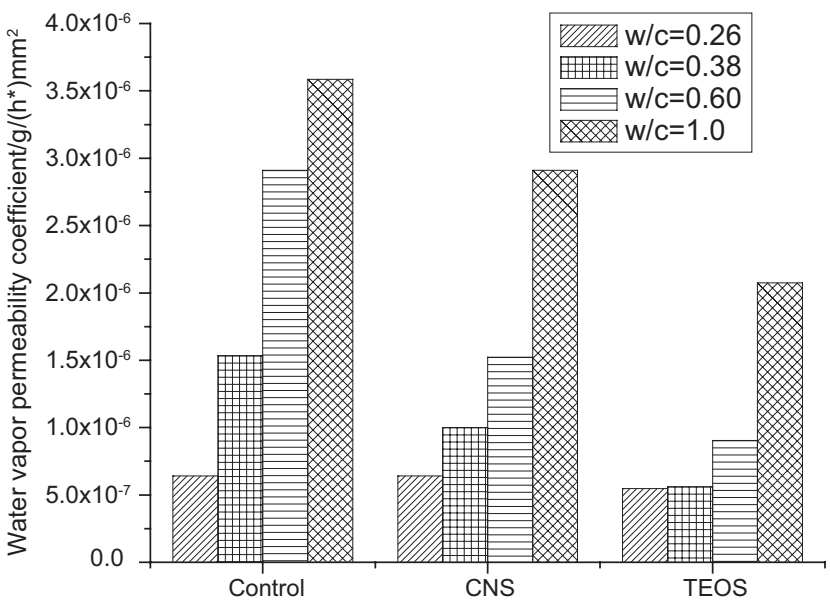

Figure 3. Effects of surface treatment of cement paste with CNS and TEOS on the water vapor transmission coefficient at different $w / c$ ratios.

\subsection{Morphology}

Influences of CNS/TEOS on the morphology of cement mortar were observed at the edge part of the cross-section (within about $2 \mathrm{~mm}$ from the edge) of the sample slice, and the typical SEM images are shown in Figure 4. It can be seen in the control sample that pores with size of about $10 \mu \mathrm{m}$ are easy to see. However, such pores become rare to find in CNS/ TEOS-treated sample, especially in the TEOS-treated sample, indicating a more significant pore-filling effect of TEOS.
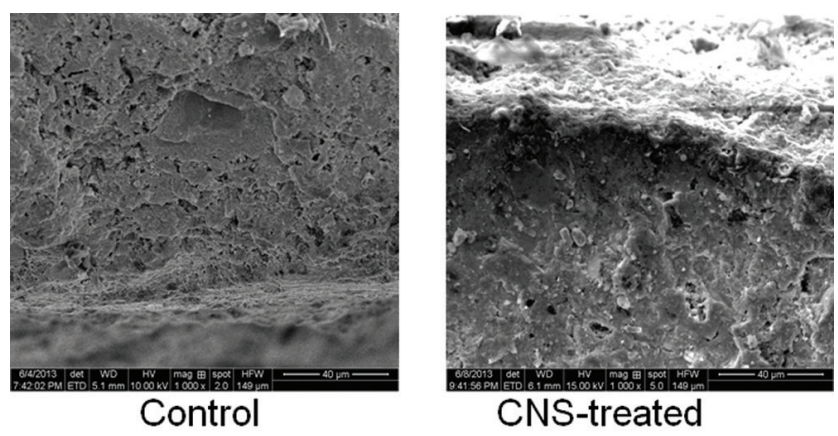

CNS-treated

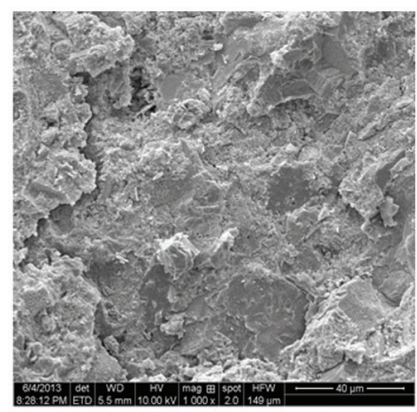

TEOS-treated

Figure 4. SEM images of CNS/TEOS-treated mortar $(\mathrm{w} / \mathrm{c}=0.6$, samples cured at $50^{\circ} \mathrm{C} / 95 \% \mathrm{RH} / 14$ days after water absorption ratio determination in Figure 2 were used). 
Pore-filling effect introduced by the penetration and condensation of CNS and condensation of penetrated and hydrosised TEOS can be clarified by the $\mathrm{Ca}$ and $\mathrm{Si}$ ion distributions as shown in Figure 5.
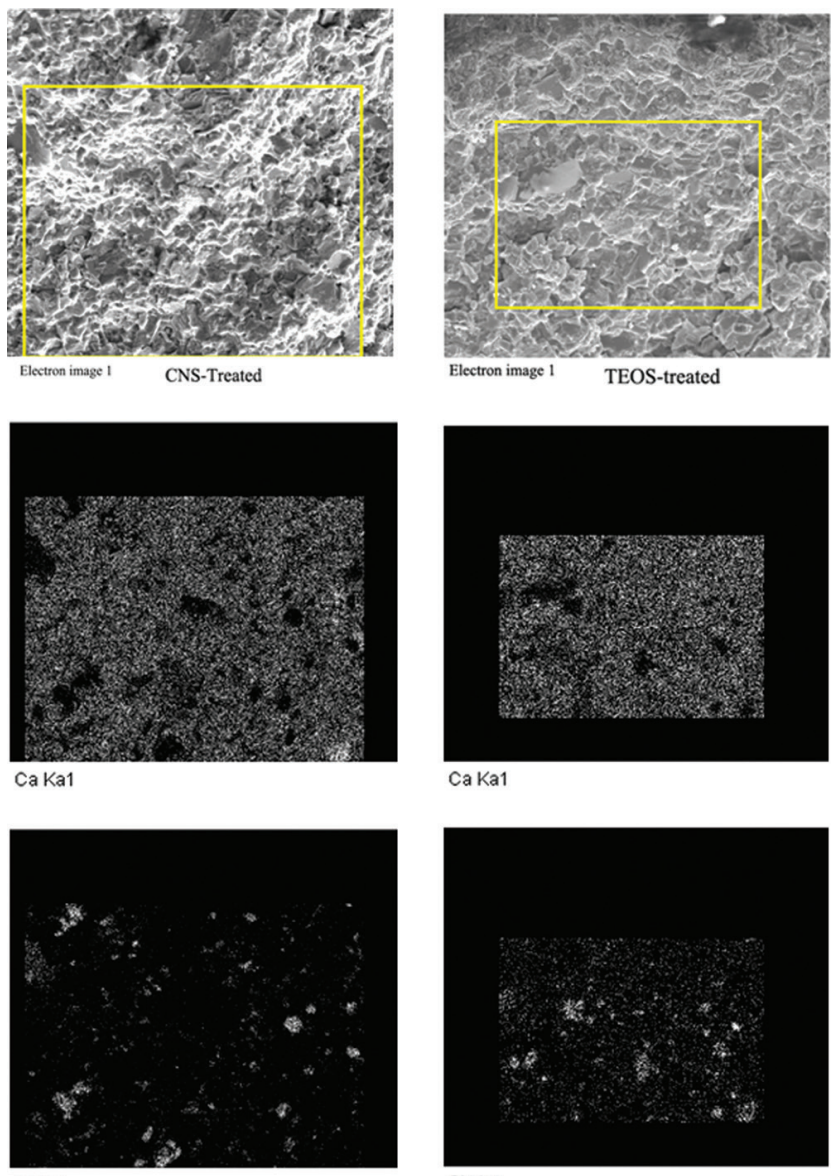

SiKa1

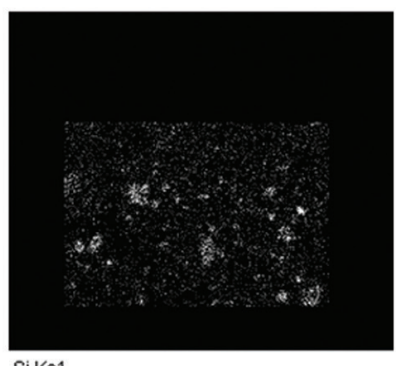

SiKa1

Figure 5. Ca and $\mathrm{Si}$ ion mapping images of CNS/TEOS-treated mortar $\left(1000 \times, w / c=0.6\right.$, samples cured at $50^{\circ} \mathrm{C} / 95 \% \mathrm{RH} / 14$ days $)$.

From the $\mathrm{Ca}$ and $\mathrm{Si}$ elemental mapping images shown in Figure 5, it can be seen that obvious "element pores" exist in Ca ion mapping image, whose positions fit with those of "Si clusters" in the Si ion mapping image very well. These observations strongly supports that the CNS and TEOS do penetrate into the pores of hardened cement mortar, and their filler effects also play a significant role in their surface sealing effect on cement-based materials.

\subsection{Minerology}

Our trial XRD tests conducted on CNS-treated sample showed that the characteristic peaks of cement hydrates were covered by amorphous $\mathrm{SiO}_{2}$ as CNS precipitates on the surface of hardened cement paste during water loss, which was also revealed from SEM test conducted by Franzoni et al. (2013), thus it is difficult to monitor the pozzolanic reaction of CNS on the surface of hardened cement-based materials by XRD. In our study, products on the surface of 1-month old mortar that was treated with CNS and cured at $50^{\circ} \mathrm{C} / 95 \% \mathrm{RH}$ for 7 days were carefully collected without disturbing the hardened cement mortar, and infrared spectroscopy (IR) was used to determine the occurrence of pozzolanic reaction of CNS.

As TEOS does not precipitate on the surface of hardened cement paste, XRD technique was used to detect its effect on the mineralogy of cement paste.

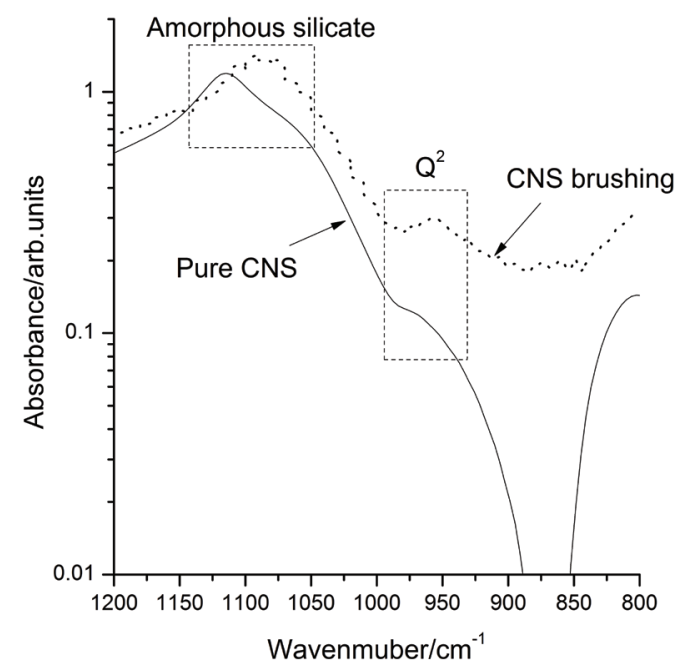

Figure 6. IR pattern of the hydration products on the surface of CNS-treated mortar (products on the surface of CNS-treated sample that was cured at $50^{\circ} \mathrm{C} / 95 \% \mathrm{RH}$ in unsealed condition for 7 days were collected and tested).

IR patterns of pure CNS and hydration products on the surface of CNS-treated mortar are shown in Figure 6. It demonstrates that apart from the strong amorphous silicate chains, the middle group silicate tetrahedral of $\mathrm{Q}^{2}$ appears (Chindaprasirt, Jaturapitakkul, \& Sinsiri, 2005) in CNS-brushing sample, indicating the occurrence of the pozzolanic reaction of nanoSiO ${ }_{2}$. The insignificant peak intensity reflects that the reaction extent is small, which could be due to its hydration reaction environment.

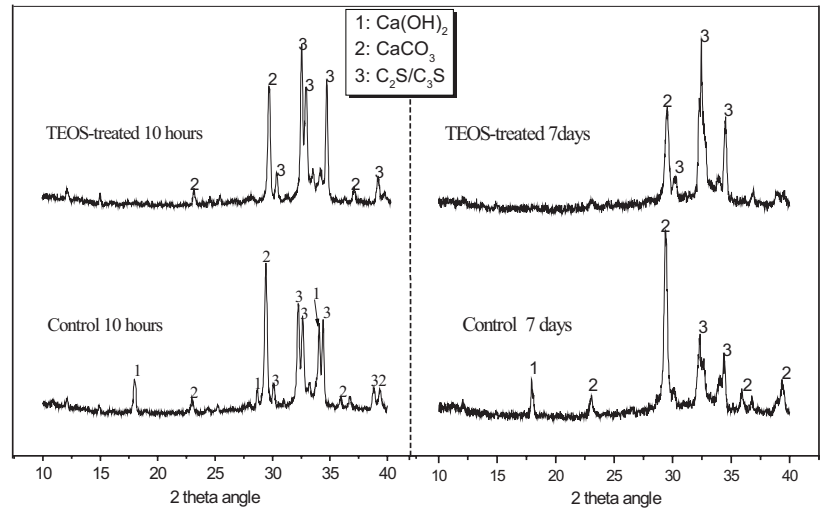

Figure 7. Superficial XRD patterns of TEOS-treated cement pastes at $10 \mathrm{~h}$ and 7 -day old. 
Figure 7 exhibits the influence of surface treatment of cement pastes with TEOS on their mineral compositions. It shows that the characteristic peak of $\mathrm{Ca}(\mathrm{OH})_{2}$ is rare to see, and the peak intensity of calcite is relatively smaller in TEOS-treated samples at both $10 \mathrm{~h}$ and 7 -day old compared with the control samples, indicating that $\mathrm{Ca}(\mathrm{OH})_{2}$ on the surface of hydrated cement paste is consumed by pozzolanic reaction of TEOS.

\subsection{Pore size distribution}

Mercury intrusion porosimetry was used to quantitatively evaluate their effects on the pore size distribution of hardened cement mortar.

It can be seen in Figure 8 that both CNS and TEOS alter the pore size distributions of mortars with $\mathrm{w} / \mathrm{c}$ ratios of 0.4 and 0.6 . It shows that the content of capillary pores with diameter of about $10 \mu \mathrm{m}$ decreases greatly when the surface treatment was applied. It also shows that gel pores with diameter between 0.01 and $0.1 \mu \mathrm{m}$ become finer in $0.4 \mathrm{w} / \mathrm{c}$ cement mortar, and the content of gel pores at this size range increases in $0.6 \mathrm{w} / \mathrm{c}$ cement mortar, both of which contribute to the densification of the coarse pores into fine ones (Jennings, Bullard, \& Thomas, 2008).

It can be seen from the $0.6 \mathrm{w} / \mathrm{c}$ cement mortar that the pore volume of TEOS-treated samples at size range from 20 to $50 \mathrm{~nm}$ is greater than the control sample, while it becomes smaller at pore size range smaller than $10 \mathrm{~nm}$, and this can be attributed to the filling of pores of size about $20-50 \mathrm{~nm}$ into pores smaller than $10 \mathrm{~nm}$. However, such phenomenon is not seen in CNStreated sample at this size range. A higher pore volume at pore size range from 20 to $50 \mathrm{~nm}$ in CNS-treated sample can be due to the filling of capillary pores with size of several microns. This comparison gives a hint on how these two pozzolans behave in pore filling of cement mortar: CNS is effective in filling capillary pores with size greater than $50 \mathrm{~nm}$, while TEOS penetrates into pores smaller than $50 \mathrm{~nm}$, and this could be the reason for its better surface treatment effect.

\subsection{Evaluation of the pore-refining effects of CNS and TEOS on the transport properties of hardened cement pastes}

It is accepted that the transport properties of cementbased material are greatly dependent on the volume, size, and morphology of capillary pores (Reinhardt \& Gaber, 1990). Water absorption rate, water vapor permeability coefficient, and MIP tests conducted on mortar samples reveal the pore-refining characteristics of CNS and TEOS. To quantitatively assess the porerefining effect on the transport properties of cementbased materials, pore size distribution of cement pastes was measured, and relationships between pore volume of various sizes and the transport properties, that is, the water vapor permeability coefficient and the initial water absorption coefficient of hardened cement pastes with w/c of $0.26,0.38,0.60$, and 1.0 were drawn, and the results are shown in Figure 9.

The scatter diagrams of the transport parameters vs. pore volume are shown in Figure 9, and the linear regressions between the transport properties with the pore volume of various sizes are also shown. As expected, a greater amount of pore volume been taken into calculation, a higher regression coefficient is resulted. For the water vapor transmission, little variation of the regression coefficient can be seen when pores with sizes ranged from 0.1 to $0.01 \mu \mathrm{m}$ and 0.01 to $0.003 \mu \mathrm{m}$ are taken into calculation. Considering the gel pores of sizes smaller than $10 \mathrm{~nm}$ contribute little to the transport properties (Mehta \& Manmohan, 1980), a reduction of capillary pores larger than 0.01 or $0.1 \mu \mathrm{m}$ will greatly improve the transport resistivity of the paste. This could be due to the existence of the networks of micropores in these size ranges that contribute to the transport of gaseous and liquid substances (Taylor, 1997). Moreover, as pores range from 0.01 to $0.1 \mu \mathrm{m}$ take a great portion
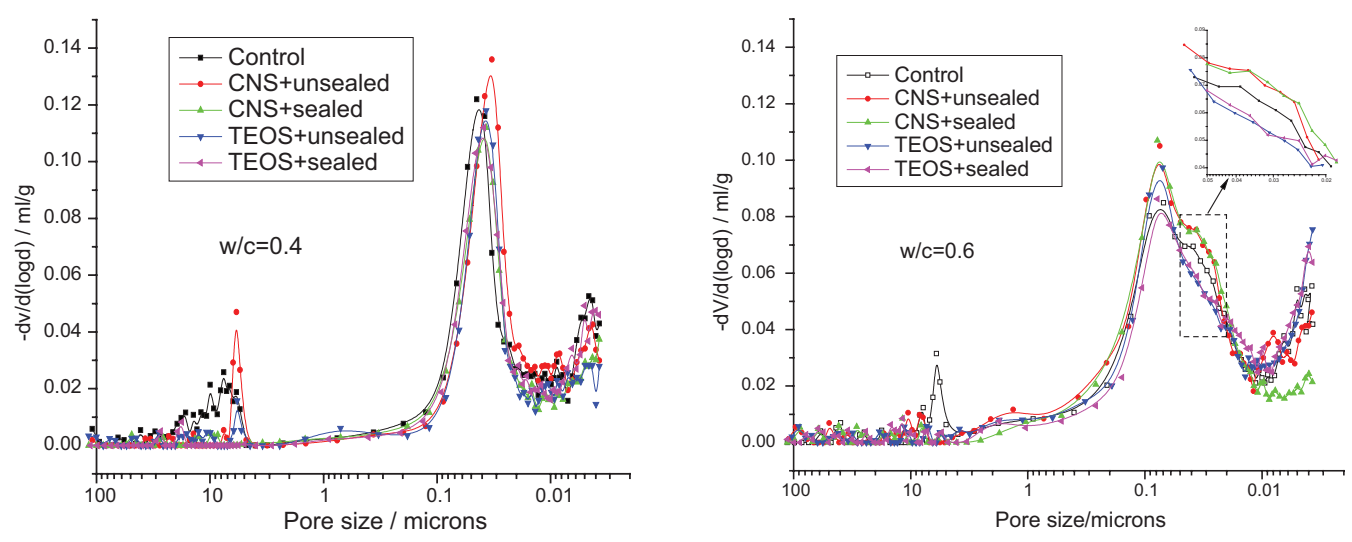

Figure 8. Pore size distribution curves of CNS/TEOS-treated mortars (cured at $50^{\circ} \mathrm{C}$ for 14 days). 


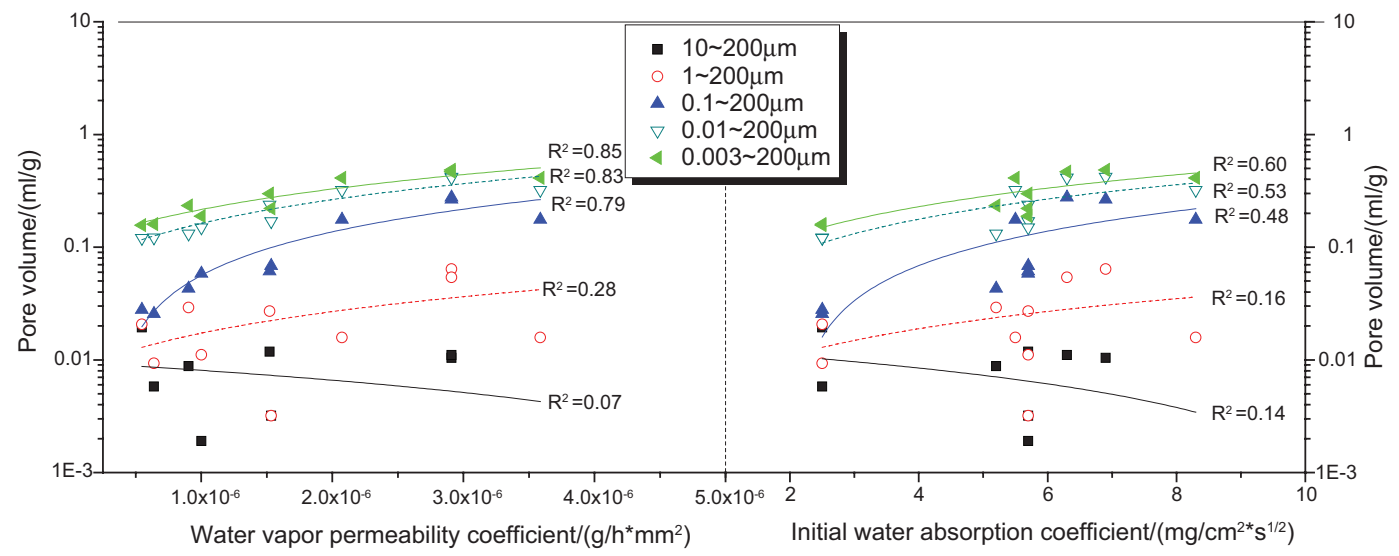

Figure 9. Relationship between the transport properties with pore volume of cement paste.

of capillary pores in mature pastes, especially in low w/c ratio samples, a greater reduction extent can be resulted in when pores in this size range are reduced.

From Figure 8 , it can be figured out that the refining of pores smaller than 0.01 or $0.1 \mu \mathrm{m}$ will linearly reduce the transport properties of hardened cement pastes, and this is in line with the statement that a high proportion of the water flow appears to be through pores wider than about $0.1 \mu \mathrm{m}$ [16]. A greater reduction of pores finer than 0.1 and $0.01 \mu \mathrm{m}$, as did in CNS or TEOS treated sample, a greater reduction of transport property of cement-based materials can be resulted.

\section{CONCLUSIONS}

Effectiveness of colloidal nanoSiO ${ }_{2}$ (CNS) and its precursor, tetraethoxysilane (TEOS), for surface treatment of hardened cement-based materials through brushing and soaking technique was investigated by studying their pozzolanic reactivity and pore-filling effect. Based on the study, the following conclusions can be drawn:

(1) CNS is effective in decreasing water absorption ratio of cement mortar at $50^{\circ} \mathrm{C}$ and in sealed curing condition, but its effect at $20^{\circ} \mathrm{C}$ is negligible, especially in unsealed curing condition. Comparing with the CNS-treated sample, a grater reduction of water absorption can be obtained in TEOS-treated sample at 20 or $50^{\circ} \mathrm{C}$, in sealed or unsealed condition.

(2) Production of additional hydrates from the pozzolanic reaction between CNS/TEOS and $\mathrm{Ca}(\mathrm{OH})_{2}$ and filler effects of CNS and TEOS contribute to the densification of the hardened cement-based materials.

(3) TEOS is more capable of filling pores finer than $50 \mathrm{~nm}$, while CNS is effective in filling pores coarser than $50 \mathrm{~nm}$, and the difference could be accounted for their difference in pore-penetration capability.

(4) CNS decreases the transport properties of hardened cement pastes mainly due to its blocking of pores larger than $0.1 \mu \mathrm{m}$. An easier penetration of TEOS than CNS into pores results in a greater reduction extent of the transport properties.

(5) Linear reduction of transport properties of hardened cement pastes can be resulted from the reduction of the capillary pores smaller than $0.1 \mu \mathrm{m}$, and this can be accounted for the reduction of the transport properties of samples treated with CNS and TEOS.

\section{ACKNOWLEDGMENTS}

Supports from Natural Science Fundation of China (No. 51302105) and Program for Scientific Research Innovation Team in Colleges and Universities of Shandong Province are acknowledged.

\section{REFERENCES}

ASTM Committee C-16. ASTM E96 - 00. (2000). Standard Test Methods for Water Vapor

Transmission of Materials. Washington.

Basheer, P. A. M., Basheer, L., Cleland, D. J., \& Long, A. E. (1997). Surface treatments for concrete: assessment methods and reported performance. Construction Building Materials, 11(7-8), 413-429.

Cardenas, H. E., \& Struble, L. (2006). Electrokinetic nanoparticle treatment of hardened cement paste for reduction of permeability. Journal of Materials in Civil Engineering, 18(4), 554-560.

Chindaprasirt, P., Jaturapitakkul, C., \& Sinsiri, T. (2005). Effect of fly ash fineness on compressive strength and pore size of blended cement paste. Cement and Concrete Composites, 27(4), 425-428. 
Delucchi, M., Barbucci, A., \& Cerisola, G. (1997). Study of the physico-chemical properties of organic coatings for concrete degradation control. Construction Building Materials, 11(7), 365-371.

Franzoni, E., Pigino, B., \& Pistolesi, C. (2013). Ethyl silicate for surface protection of concrete: Performance in comparison with other inorganic surface treatments. Cement and Concrete Composites, 44, 69-76.

Jennings, H., Bullard, J., Thomas, J., et al. (2008). Characteristics and modeling of pores and surfaces in cement paste: Correlations to processing and properties. Journal of Advanced Concrete Technology, 6, 1-25.

Jiang, Z., Long, G., \& Sun, Z. (2009). Concrete rehabilitation: mechanisms, techniques and materials. Beijing: Chemistry and Industry Press.

Khatib, J., \& Mangat, P. (1995). Absorption characteristics of concrete as a function of location relative to casting position. Cement and Concrete Research, 25(5), 999-1010.
Mehta, P., \& Manmohan, P. (1980). Pore size distribution and permeability of hardened cement pastes. Proceedings of the 7th International Conference on Chemistry of Cements, Paris, Vol. III, 1-5.

Reinhardt, H., \& Gaber, K. (1990). From pore size distribution to an equivalent pore size of cement mortar. Materials and Structure, 23(1), 3-15.

Sandrolini, F., Franzoni, E., \& Pigino, B. (2012). Ethyl silicate for surface treatment of concrete - Part I: Pozzolanic effect of ethyl silicate. Cement and Concrete Composites, 34, 306-312.

Scarfato, P., Maio, L., \& Fariello, M. (2012). Preparation and evaluation of polymer/clay nanocomposite surface treatments for concrete durability enhancement. Cement and Concrete Composites, 34, 297-305.

Taylor, H. (1997). Cem Chem, 274.

Yu, P., Kirkpatrick, J., Poe, B., et al. (1999). Structure of calcium silicate hydrate (C-S-H) near-, mid-, and far-infrared spectroscopy. Journal of the American Ceramic Society, 82(3), 742-748. 